\title{
The implications of labor market network for business cycles
}

\author{
Marcelo Arbex (University of Windsor) \\ Sydney Caetano (Universidade Federal de Juiz de Fora) \\ Dennis O'Dea (University of Washington)
}

Working paper $16-03$

Working papers are in draft form. This working paper is distributed for purposes of comment and discussion only. It may not be reproduced without permission of the copyright holder. Copies of working papers are available from the author or at http://ideas.repec.org/s/wis/wpaper.html. 


\section{The implications of labor market network for business cycles}

\author{
Marcelo Arbex* \\ Sidney Caetano ${ }^{\dagger}$ \\ Dennis O’Dea
}

January 13, 2016

Keywords: Business Cycles; Labor Markets; Social networks; Job search.

JEL Classification: D85; E24; E32; J64.

* Corresponding author. Department of Economics, University of Windsor. arbex@uwindsor.ca.; †Faculdade de Economia, Universidade Federal de Juiz de Fora. sidney.caetano@ufjf.edu.br; $\ddagger$ Department of Economics, University of Washington. odea@uw.edu. Any errors are our own. 


\section{Introduction}

We reconsider a conventional framework of a real business cycle model with job search (e.g., Merz (1995), Andolfatto (1996)) in which we embed a social network model along the lines of models of the transmission of job offers in large, complex networks (Calvo-Armengol and Jackson (2004)). In our model, workers are endowed with peers exogenously and engage in network search to affect their labor market outcomes, a channel absent from most previous quantitative studies of business cycles. ${ }^{1}$ We derive a matching function using the mean-field approach (Vega-Redondo (2007)) to take into account network and direct search efforts by workers in a complementary manner. ${ }^{2}$ Network in the labor market and the complementarity of search efforts (by the unemployed) reduce informational and search frictions and amplify the response of output and employment to a technological shock.

Our approach is consistent not only with labor-market stylized facts and business cycles features, but also with empirical evidence pointing towards the importance of networks in the labor market as an information transmission mechanism. At least one third of employees find job through their social contacts, workers with more social contacts are on average more likely to be employed, more likely to receive and pass a job opportunity, and be better paid when employed (for excellent surveys of the literature, see Ioannides and Datcher Loury (2004) and Topa (2011)). We assume power-law distributions, as these networks have a number of attractive features that match well many properties of empirical social networks (Jackson (2008)). In our model, even though job search efforts are exogenously given, social contacts provide individuals with the opportunity to learn about vacancies faster. The additional channel through which workers can find jobs (i.e., network search) does not trigger a virtuous circle but has important quantitative consequences for the business cycle, as it amplifies the economy's short-run response to a productivity shock, that cannot be ignored.

\section{The Model}

\subsection{Demography, Network Search and Employment}

In a typical household there are a measure $n_{t}$ of employed family members and a measure $1-n_{t}$ of unemployed family members. Employed members supply labor hours $l_{t}$. Unemployed workers search for jobs actively making an exogenous (time) effort $e$ and spend time $x$ in social activities, which develops their social connections, increasing the strength of their ties to their peers.

Workers are connected to one another in a social network, which structure is exogenous. Each

\footnotetext{
${ }^{1}$ Models with search frictions, wage bargaining and efficiency have also improved our understanding of the business cycle (for instance, Hairault (2002) and Cheron and Langot (2004), among others). For search and matching labor market frictions into a New Keynesian model see Christiano et al. (forthcoming)

${ }^{2}$ For alternative matching models with social networks, see for instance, Calvo-Armengol and Zenou (2005), Ioannides and Soetevent (2006), and Fontaine (2007).
} 
agent may have peers to whom she passes information when employed, and from whom she may receive information when unemployed. A network is described by a degree distribution $\left\{D_{z}\right\}_{z=1}^{\infty}$, where $D_{z}$ is the proportion of agents who have $z \in[1, \infty)$ peers. $^{3}$. We assume power-law distributions (workers with many links are more likely to have access to job information) and apply the mean field approach (Vega-Redondo (2007)). ${ }^{4}$

The probability a given agent has $s$ peers is $\psi_{s}=\left(s D_{s}\right) /\langle z\rangle$, where $\langle z\rangle=\int_{z=1}^{\infty}\left(z D_{z}\right) d z$ is the average degree in the network. Note that $\psi_{s} \neq D_{s}$, i.e., the probability one of your peers has $s$ links is not equal to the proportion of the population that has $s$ links. This is because agents with many peers, and a large $s$, are disproportionately likely to be your peers, so we must scale $D_{s}$ by $s /\langle z\rangle$. This gives the probability that a peer with $s$ links passes a worker a job. The employment rate among those workers with $s$ peers is $n_{s}$. Each employee contacts unemployed friends with a probability $\rho_{t}$ (Fontaine (2007))

The rate at which job information is passed from employed workers to their unemployed peers depends on how much effort, $x$, agents spent on social activities, i.e., $\varphi\left(x_{t}\right)=x^{1-\lambda}$, where $\lambda$ measures the efficacy of this technology ${ }^{5}$. Employed workers pass job information to peers with probability $\varphi(x) / s$.

Integrating over all possible $s$, the probability a worker is passed job information from a peer is therefore

$$
\Omega_{t}=\int_{s=1}^{\infty} \rho_{t} \frac{\varphi(x)}{s} n_{s, t} \psi_{s} d s=\rho_{t} \frac{\varphi(x)}{\langle z\rangle} n_{t}
$$

Hence, the probability a worker of type $z$ receives at least one offer via a peer in his social network is $p_{t}=1-\left(1-\Omega_{t}\right)^{z}$. And the aggregate probability workers of different types $z$ receive job offers via their network peers is

$$
P_{t}=\int_{z=1}^{\infty} p_{t} D_{z} d z .
$$

Meetings between jobs and workers are stochastic, and are modeled by means of a standard matching function embedded with network search as follows

$$
M_{t}=v_{t}^{\alpha}\left[\left(1-n_{t}\right)\left(e^{\gamma} P_{t}^{(1-\gamma)}\right)\right]^{1-\alpha}, \quad 0 \leq \alpha \leq 1,0 \leq \gamma \leq 1
$$

where $M_{t}$ represents the number of job matches that are created in time period $t$ and $\gamma$ is the relative weight of direct search on the aggregate job arrival rate, $\left(1-n_{t}\right) e^{\gamma} P_{t}^{(1-\gamma)}$.

\footnotetext{
${ }^{3}$ This is common to approximate the discrete number of network connections with a continuous variable, so rather than $z \in 1, \ldots, \infty$ we use this half-closed interval.

${ }^{4}$ This approach relies on the assumption that there are no systemic differences between each worker's local neighborhoods (homogenous mixing). Because the network is large, an agent could not infer anything about their employment status beyond the average in the network.

${ }^{5}$ Galeotti and Merlino (2014) investigate the implications of the feedback between labor market conditions and investment (time and effort) in social networks in matching vacancies with job seekers.
} 
Following Pissarides (1990), the aggregate employment evolves according to the dynamic equation:

$$
n_{t+1}=(1-\sigma) n_{t}+M_{t}
$$

where $\sigma \in(0,1)$ is the exogenous job separation rate (independent across agents).

\subsection{Households, Firms and the Economy's Resource Constraint}

Preferences of the household are represented by the following utility function

$$
E_{0} \sum_{t=0}^{\infty} \beta^{t}\left[\log \left(c_{t}\right)+n_{t} \phi_{1} \frac{\left(1-l_{t}\right)^{1-\eta}}{(1-\eta)}+(1-n) \phi_{2}\left(\gamma \frac{(1-e)^{1-\eta}}{(1-\eta)}+(1-\gamma) \frac{(1-x)^{1-\eta}}{(1-\eta)}\right)\right]
$$

where $E$ denotes the expectation operator, $\beta$ is the discount rate which lies in $(0,1), c_{t}$ is consumption, $\phi_{1}, \phi_{2}$ are the weight on leisure depending on the household's employment status and $\eta \neq 1$.

Job-worker pairs are formed as a firm undertakes recruiting activities, and, on the other hand, unemployed workers search directly for a job or learn about it through their networks. Let $v_{t}$ be the total number of new jobs made available by firms during the period $t$, each vacancy incurring a flow cost equal to $\kappa>0$, measured in units of physical output.

Output $y_{t}$ is produced according to a standard neoclassical production technology $F\left(k_{t}, n_{t} l_{t} ; \varepsilon_{t}\right)=$ $\exp \left(\varepsilon_{t}\right) \Psi k_{t}^{\theta}\left(n_{t} l_{t}\right)^{1-\theta}$, where $k_{t}$ is the capital stock, $0 \leq \theta \leq 1, \Psi>0$, and $\varepsilon_{t}$ evolves as an $\operatorname{AR}(1)$ process: $\varepsilon_{t}=\rho_{\epsilon} \varepsilon_{t-1}+\tilde{\epsilon}_{t}$, where $0<\rho<1$. The aggregate resource constraint of the economy must be satisfied

$$
c_{t}+k_{t+1}+\kappa v_{t}=y_{t}+(1-\delta) k_{t}
$$

\subsection{Planner's Problem and a Decentralized Network Search Economy}

In this environment the social welfare problem is to choose a contingency plan $\left\{c_{t}, l_{t}, k_{t+1}, n_{t}, v_{t}\right\}_{t=0}^{\infty}$ in order to maximize (5) subject to the resource constraint, equation (6), the law of motion for employment in (4), the law of motion for the productivity shock and an initial condition $\left(k_{0}, n_{0}, \epsilon_{0}\right)$.

The firms' and household's problems are similar to the ones agents face in an economy with search only, for instance as in Andolfatto (1996) and Merz (1995), and the planner's optimal allocation decisions can be implemented as a stationary equilibrium of a decentralized network search economy. A key implication of social networks in the labor market is most apparent in the equilibrium wage equation, which now takes into account that fact that workers can reach firms 
job vacancies through their peers:

$$
\begin{aligned}
w_{t} & =(1-\xi)(1-\theta) \exp \left(\varepsilon_{t}\right) \Psi k_{t}^{\theta}\left(n_{t} l_{t}\right)^{-\theta} \\
& -\frac{\xi c_{t}}{l_{t}}\left(\phi_{1} \frac{\left(1-l_{t}\right)^{1-\eta}}{1-\eta}-\phi_{2} \gamma \frac{(1-e)^{1-\eta}}{1-\eta}-\phi_{2}(1-\gamma) \frac{(1-x)^{1-\eta}}{1-\eta}\right. \\
& \left.-\mu_{t}\left((1-\alpha) \chi v_{t}^{\alpha}\left(\left(1-n_{t}\right) e^{\gamma} P_{t}^{1-\gamma}\right)^{-\alpha} e^{\gamma} P_{t}^{1-\gamma}\right)\right)
\end{aligned}
$$

where $0<\xi<1$ denotes the firm's share of the value of a job that forms in the network search equilibrium.

\section{Numerical Results}

\subsection{Calibration}

Table I presents our baseline calibration parameters taken from Andolfatto (1996). We set $\gamma=0.40$ (Holzer (1988), Ioannides and Datcher Loury (2004)). Time effort looking for a job is split between direct search and network search as follows: $e=x=(1 / 4) l^{*}$, keeping the total amount of time an agent gives up in terms of leisure the same, i.e., $(1 / 2) l^{*}$. In a search economy $(\gamma=1) e=(1 / 2) l^{*}$, while in a network economy, workers make an equivalent "socializing" effort, $x=(1 / 2) l^{*}$, where $\gamma=0$. We assume that agents have on average five peers, $\langle z\rangle=5$, and the network search effort is very efficient by setting $\lambda=0.95$. The power-law network has distribution $D_{z}=(a-1) z^{-a}$, with $a=2.25$. We assume that the probability an employee contacts unemployed friends is $\rho_{t}=v_{t} / n_{t}$.

Table I: Model parameters

\begin{tabular}{ccccccccccc}
\hline \multicolumn{1}{c}{ Preferences } & \multicolumn{4}{c}{ Production technology } & \multicolumn{4}{c}{ Network Search technology } \\
\hline \multicolumn{2}{c}{$\eta$} & $\boldsymbol{\eta}$ & $\delta$ & $\rho_{\epsilon}$ & $\sigma_{\tilde{\epsilon}}$ & $\sigma$ & $\alpha$ & $\lambda$ & $a$ & $\langle z\rangle$ \\
0.99 & 2.00 & 0.36 & 0.025 & 0.95 & 0.007 & 0.15 & 0.60 & 0.95 & 2.25 & 5 \\
\hline
\end{tabular}

\subsection{Results}

The impulse response functions to a one standard deviation productivity shock are reported in Figure 1. A technological shock propagates in a network economy in a similar fashion it does in a search economy. However, a network labor market and the complementarity of network search and direct search by the unemployed amplify the response of unemployment and vacancies to a shift in productivity.

A temporary increase in productivity increases the value of a match, which leads firms to post more vacancies and raises workers' finding rate. As is standard in the literature, we also observe that hours, output and labor productivity all go up after a positive temporary technology (Shimer (2005)). Network search help to reduce informational deficiencies in the labor market an unemployed worker network affects how quickly he can expect to receive such additional job 

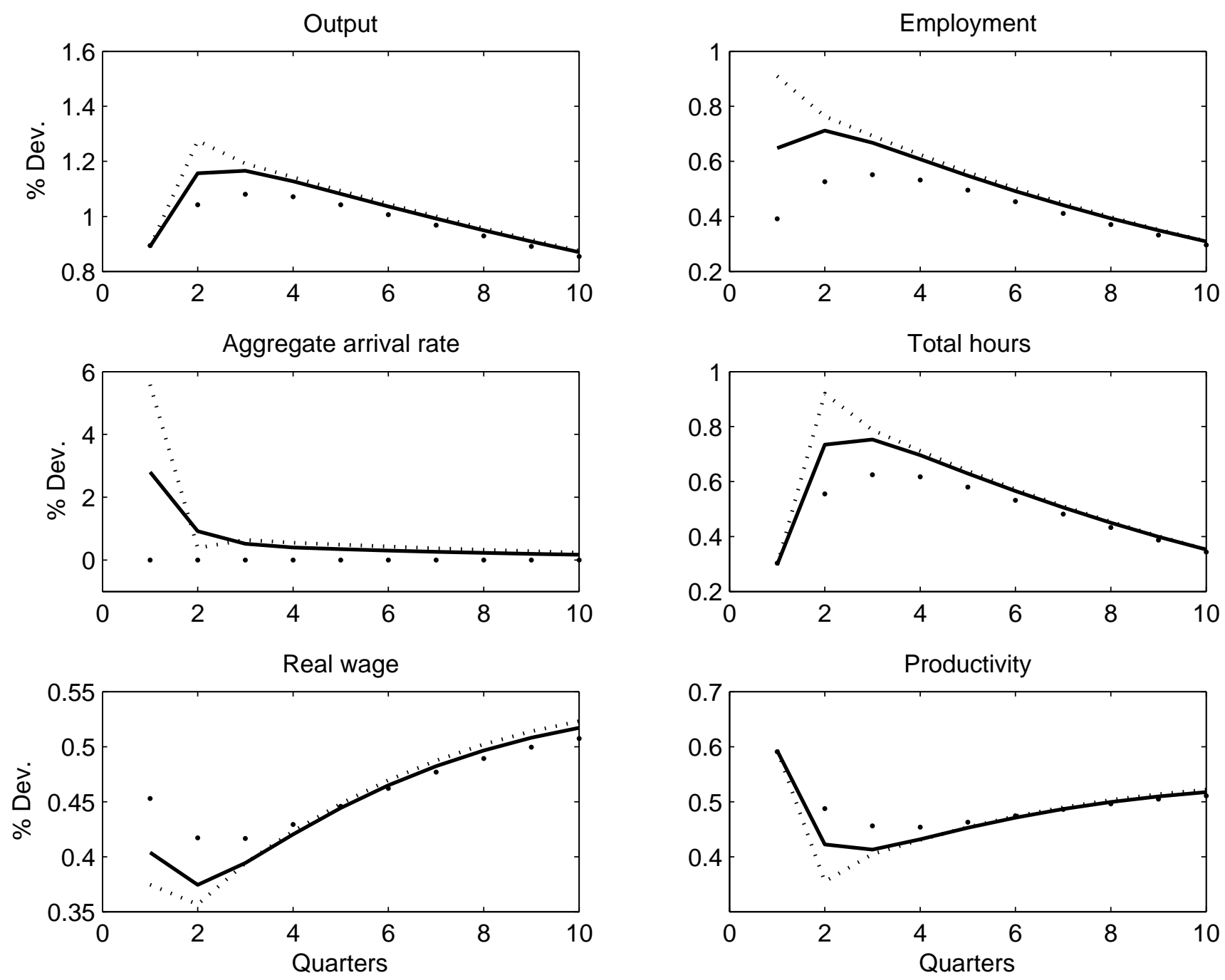

- Search ...... Network - Network Search

Figure 1: Impulse Response Functions

information from a peer as employed workers represent an additional recruitment tools for firms when the economy is expanding. Hence, the productivity increase leads to a larger aggregate job search effort by the unemployed, which reduces the value of such status and, consequently, the increase in the wage. The smaller increase in the wage improves the value of an employee for a firm and thus increase the response of vacancies. Then, the effects of the positive productivity shock dies out and the economy returns to its initial steady state. Since both network search and direct search are exogenously given such shock does not trigger a sort of virtuous circle observed in Gomme and Lkhagvasuren (2015), who show that endogenous job search effort can serve as a strong amplification mechanism. However, the amplification of the response obtained in the network search model cannot to be obtained by just increasing search effort in a direct search only model.

The business cycles properties of a network economy are, however, qualitatively similar to 
those observed in labor market search models (Table II). But there are some improvements. For instance, the contemporaneous correlation between hours worked and productivity drops to 0.71, compare to 0.81 found in a search model (Andolfatto (1996)) and to the 0.95 predicted by the RBC model ${ }^{6}$.

Table II: Cyclical Properties: U.S. Economy and Model Economies

\begin{tabular}{|c|c|c|c|c|c|}
\hline & \multirow{2}{*}{$\begin{array}{c}\text { U.S. } \\
\text { economy }\end{array}$} & \multirow{2}{*}{$\begin{array}{c}\text { Search } \\
\text { economy }\end{array}$} & \multirow{2}{*}{$\frac{\text { Network economy }}{\gamma=0.00}$} & \multicolumn{2}{|c|}{ Network Search economy } \\
\hline & & & & $\bar{\gamma}=0.40^{2}$ & $\gamma=0.40^{3}$ \\
\hline Consumption & 0.56 & 0.3172 & 0.3043 & 0.3098 & 0.3098 \\
\hline Investment & 3.14 & 3.0145 & 3.1051 & 3.0648 & 3.0647 \\
\hline Total hours & 0.93 & 0.6048 & 0.7143 & 0.6727 & 0.6726 \\
\hline Employment & 0.67 & 0.5405 & 0.7220 & 0.6524 & 0.6522 \\
\hline Hours/worker & 0.34 & 0.2185 & 0.1762 & 0.1875 & 0.1876 \\
\hline Wage bill & 0.97 & 0.9463 & 0.9758 & 0.9597 & 0.9597 \\
\hline Labor's share & 0.68 & 0.0984 & 0.1317 & 0.1189 & 0.1189 \\
\hline Productivity & 0.64 & 0.4524 & 0.3830 & 0.4060 & 0.4060 \\
\hline Real Wage & 0.44 & 0.3849 & 0.3214 & 0.3401 & 0.3402 \\
\hline$\sigma_{y}$ & 1.58 & 1.4237 & 1.5753 & 1.5157 & 1.5156 \\
\hline
\end{tabular}

Note: $\sigma_{y}$ is the percentage standard deviation in real per-capita output;

(1) report the cyclical properties of our work when $\gamma=1$ and $e=(1 / 2) l^{*}$.

Network economy $x=(1 / 2) l^{*}$ and $\langle z\rangle=5$ is average number of peers.

Network Search: $(2) e=(2 / 6) l^{*}, x=(1 / 6) l^{*} ;(3) e=(1 / 4) l^{*}, x=(1 / 4) l^{*}$.

\section{Conclusion}

We have shown that network search effort by the unemployed can amplify the response of economic aggregates to a technological shock. The model is capable of replicating key labor market stylized facts, for instance, the negative correlation between unemployment and job vacancies is negative, employment is more volatile than labor productivity and the real wage, and labor's share of output behaves countercyclically. The main contribution of this paper is to show that labor market networks, together with direct search, have important quantitative consequences for the business cycle.

\section{Acknowledgments}

We are especially grateful to Johannes Pfeifer for comments about the codes.

\footnotetext{
${ }^{6}$ The main results of the paper are not significantly different for a range of alternative values for the network parameters $(\lambda, a)$, as well as search efforts $(e, x)$.
} 


\section{References}

Andolfatto, D. (1996): "Business Cycles and Labor-Market Search," American Economic Review, 86, 112-32.

Calvo-Armengol, A. And M. O. Jackson (2004): "The Effects of Social Networks on Employment and Inequality," American Economic Review, 94, 426-454.

Calvo-Armengol, A. And Y. Zenou (2005): "Job matching, social network and word-ofmouth communication," Journal of Urban Economics, 57, 500-522.

Cheron, A. And F. Langot (2004): "Labor Market Search and Real Business Cycles: Reconciling Nash Bargaining with the Real Wage Dynamics," Review of Economic Dynamics, 7, 476-493.

Christiano, L. J., M. S. Eichenbaum, and M. Trabandt (forthcoming): "Unemployment and Business Cycles," Econometrica.

Fontaine, F. (2007): "A simple matching model with social networks," Economics Letters, 94, 396-401.

Galeotti, A. And L. P. Merlino (2014): "Endogenous job contact networks," International Economic Review, 55, 1201-1226.

Gomme, P. And D. Lkhagvasuren (2015): "Worker search effort as an amplification mechanism," Journal of Monetary Economics, 75, 106-122.

Hairault, J.-O. (2002): "Labor-Market Search and International Business Cycles," Review of Economic Dynamics, 5, 535 - 558 .

Holzer, H. (1988): "Search Method Use by Unemployed Youth," Journal of Labor Economics, $6,1-20$.

IoAnnides, Y. M. AND L. DATCher Loury (2004): "Job Information Networks, Neighborhood Effects, and Inequality," Journal of Economic Literature, 42, 1056-1093.

Ioannides, Y. M. And A. R. Soetevent (2006): "Wages and Employment in a Random Social Network with Arbitrary Degree Distribution," American Economic Review, 96, 270-274.

Jackson, M. O. (2008): Social and Economic Networks, Princeton, NJ, USA: Princeton University Press.

Merz, M. (1995): "Search in the labor market and the real business cycle," Journal of Monetary Economics, 36, 269 - 300. 
Pissarides, C. A. (1990): Equilibrium unemployment theory, Basil Blackwell Oxford, UK ; Cambridge, Mass.

Shimer, R. (2005): "The Cyclical Behavior of Equilibrium Unemployment and Vacancies," American Economic Review, 95, 25-49.

Topa, G. (2011): "Chapter 22 - Labor Markets and Referrals," North-Holland, vol. 1 of Handbook of Social Economics, 1193 - 1221.

Vega-Redondo, F. (2007): Complex social networks, 44, Cambridge University Press. 